\title{
EDIÇÃO DO CADERNO FOTOCOPIADO 2
}

\author{
Patricia Silva Pinto'; Patrício Nunes Barreiros ${ }^{2}$ \\ 1. Bolsista PROBIC/UEFS, Graduanda em Letras com Espanhol, Universidade Estadual de Feira de Santana, e-mail: \\ patriciasilvapinto@gmail.com \\ 2. Orientador, Departamento de Letras e Artes, Universidade Estadual de Feira de Santana, e-mail: \\ patriciobarreiros@hotmail.com
}

PALAVRAS-CHAVE: Edição; Caderno Fotocopiado 2; Eulálio Motta.

\section{INTRODUÇÃO}

O projeto de pesquisa Edição e estudo das obras inéditas de Eulálio Motta tem como objetivo editar e publicar nove obras inéditas, identificadas por Barreiros (2009), do autor Eulálio de Miranda Motta (1907-1988). O presente trabalho busca editar os textos manuscritos contidos no Caderno fotocopiado 2, utilizando-se da transcrição semidiplomática dos textos, passo inicial para qualquer trabalho filológico (SPINA, 1999; CAMBRAIA, 2005; BARREIROS, 2012), pois esse tipo de edição procura reproduzir ao máximo as particularidades gráficas do texto, buscando a fidedignidade e a acessibilidade necessárias.

Os Caderno fotocopiado 2 é composto por uma fotocopia colorida do caderno, encadernada em espiral, com uma capa plástica azul transparente, contém 155 fólios escritas no reto e no verso, contendo textos manuscritos em tinta azul preta e vermelha, sendo empregados símbolos e operadores da crítica genética adaptados aos critérios de edição das obras de Eulálio Motta (BARREIROS, 2012), utilizando-se o método filológico da Crítica Textual Moderna seguindo os critérios de edição das obras de Eulálio Motta estabelecidos por Barreiros (2007) e reformulados pelo mesmo autor em 2012.

Assim, o presente trabalho se faz importante por contribuir para a edição e estudo das obras inéditas de Eulálio Motta, além de ampliar os conhecimentos acerca do escritor baiano.

\section{MATERAIS E MÉTODOS}

O corpus da pesquisa constitui-se de 155 fólios do Caderno fotocopiado 2 que contém textos manuscritos no reto e no verso. Os textos foram escritos na década de 1950 e se tratam de rascunhos de cartas para amigos, políticos e familiares, crônicas, anotações de leituras e ensaios sobre literatura.

No primeiro momento realizou-se a digitalização do caderno para facilitar a edição semidiplomártica dos textos que foram transcritos linearmente, acompanhando a topografia dos mesmos. O material está disposto da seguinte maneira: fac-símile à esquerda e a transcrição à direita. A pesquisa se utilizou do método filológico da Crítica Textual Moderna (CAMBRAIA, 2005; SPAGGIARI; PERUGI, 2004; SPINA, 1994) e dos critérios e princípios de edição das obras de Eulálio Motta estabelecidos por Barreiros (2012; 2015). Fez-se necessária o emprego dos símbolos operadores da crítica genética, segundo os critérios apresentados por Barreiros (2012): esquerda;

a)Indica-se o numero do fólio; As linhas são numeradas de cinco em cinco à margem

b) Os textos são transcritos em fonte Times New Roman padrão Word; de tamanho 11, alinhado à margem esquerda;

c) Transcreve-se o texto como se encontra no original;

d) São mantidos a ortografia, a acentuação, o uso de maiúsculas e a pontuação;

e) São utilizados símbolos para indicar trechos, palavras e letras ilegíveis; escritas fora da pauta;

f) São utilizadas e notas de pé de página para indicar informações complementares tais como: alternância da cor da tinta, emprego de símbolos e numeração de página, etc. 


\section{OS SÍMBOLOS UTILIZADOS NAS EDIÇÕES SEMIDIPLOMÁTICAS}

1. \{ \} seguimento riscado, cancelado;

2. $\{\dagger\}$ seguimento ilegível;

3. $\{\dagger\} / \backslash$ segmento ilegível substituído por outro legível na relação \{ilegível $\}$ /legível\;

4. \{ \} / substituição por sobreposição, na relação \{substituído\} /substitutol;

5. \{\}$[\uparrow]$ riscado e substituído por outro na entrelinha superior;

6. [ ] acréscimo no curso da linha;

7. [ $\uparrow]$ acréscimo na entrelinha superior;

8. [ $\downarrow]$ acréscimo na entrelinha inferior;

9. $[\uparrow\{\}]$ acréscimo na entrelinha superior riscado;

10. $[\uparrow\{\uparrow\}]$ acréscimo na entrelinha superior ilegível;

11. $[\uparrow\{\uparrow\} / \backslash]$ acréscimo na entrelinha superior ilegível e substituído por outro na sequência;

12. $[\downarrow\{\dagger\} / \backslash$ acréscimo na entrelinha inferior ilegível e substituído por outro na sequência;

13. [*个] parte do texto localizada à margem superior indicada pelo autor através de seta, linha ou números remissivos;

14. $[* \downarrow]$ parte do texto localizada à margem inferior indicada pelo autor através de seta, linha ou números remissivos;

15. / * / leitura conjecturada;

16. ( ) intervenção do editor (acréscimos e informações);

\section{RESULTADOS E DISCUSSÃO}

O Caderno foto copiado 2 consiste em um conjunto de textos manuscritos que versam acerca de temas como política, religião, questões do cotidiano e o comportamento humano. Os escritos de Eulálio Motta compõem um total de nove textos distribuídos em 22 folhas com reto e verso, exceto pela folha 22 que só tem o reto. Os tipos textuais que compõem os escritos são: crônicas cartas poemas e seleções de versículos bíblicos.

Figura 01: Exemplo de Edição f. 22r

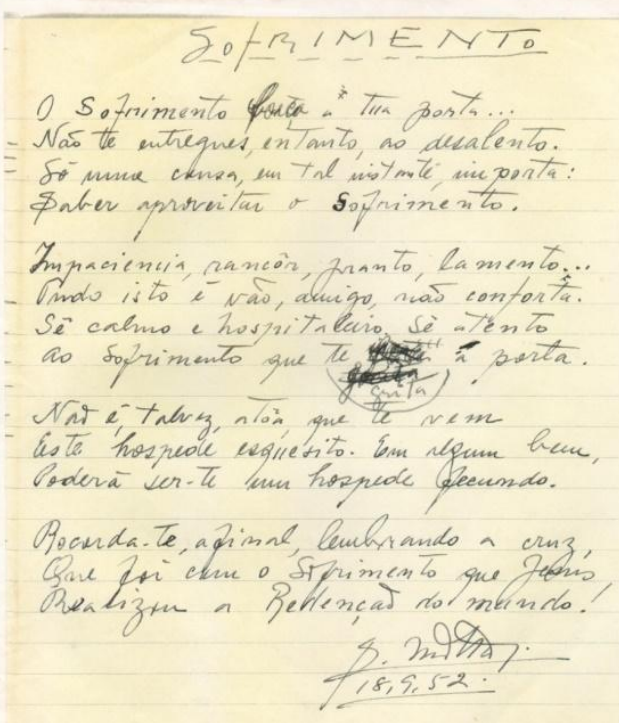

Sofrimento

O sofrimento $\{$ bate $\}$ /forçal a tua porta...

Não te entregues, entanto, ao desalento.

Só uma cousa, em tal instante, importa:

Saber aproveitar o Sofrimento.

Impaciencia, rancor, pranto, lamento...

Tudo isto é vão, amigo, não conforta.

Sê calmo e hospitaleiro. Sê atento

Ao Sofrimento que te $\{\dagger\}[\downarrow\{\dagger\} /$ grital $\}$ à porta.

Não é talvez, atôa quete vem

Este hospede esquisito. Em algum bem,

Poderá ser-te um hospedefecundo.

Recorda-te, afinal, lembrando a cruz,

Que foi com Sofrimento que Jesus

15

Realizou a Redenção do mundo!

[ ]

18.9 .52 


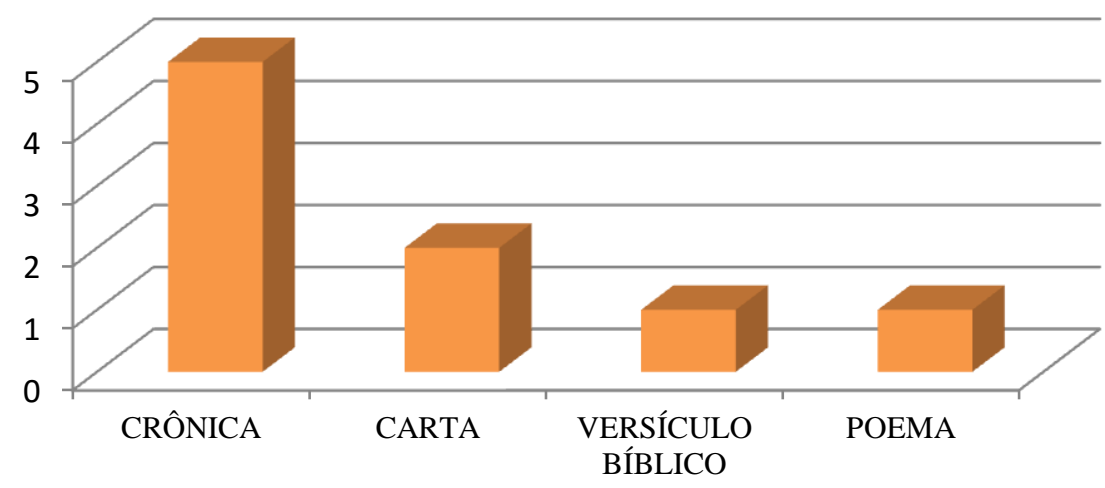

DISPOSIÇÃO DOS TEXTOS EDITADOS

Fonte: Elaborado pelo pesquisador

Os textos encontrados do Caderno fotocopiado 2 foram escritos durante ano de 1952 , se apresentam em bom estado de conservação, contudo a dificuldade encontrada durante a transcrição está na leitura da caligrafia do autor. Durante a realização do trabalho se observou que algumas palavras possuem grafia diferente da atualidade.

\section{CONSIDERAÇÕES FINAIS}

A transcrição semidiplomática do Caderno Fotocopiado 2 traz uma valiosa contribuição para a edição das obras literárias inéditas de Eulálio Motta, isso porque esses manuscritos constam testemunhos de textos literários e importantes documentos paratextuais que certamente irão elucidar a obra do escritor mundonovense. Temas tratados nas obras do escritor como política religião e situações do cotidiano auxiliam na compreensão não apenas de quem foi Eulálio Motta mas também na compreensão da mentalidade da época, contribuindo assim com estudos na área da Crítica Textual e dos estudos literários.

\section{REFERÊNCIAS}

BARREIROS, Patrício N. O pasquineiro da roça: a hiperedição dos panfletos de Eulálio Motta. Feira de Santana: EDUEFS, 2015.

BARREIROS, Patrício N. Sonetos de Eulálio Motta. Feira de Santana: EDUEFS, 2012.

BARREIROS, Patrício N. A oficina do escritor e os projetos editorais de Eulálio de Miranda Motta. In: Anais do XIII Congresso Nacional de Linguística e Filologia. Rio de Janeiro: EDUERJ, v. XIII, n. 04, 2009, p. 1465-1480.

CAMBRAIA, César Nardelli. 2005. Introdução à crítica textual. São Paulo: Martins Fontes. SPAGGIARI, Barbara; PERUGI, Maurizio. Fundamentos da crítica textual. Rio de Janeiro: Lucerna, 2004.

SPINA, Segismundo. Introdução à edótica: crítica textual. 2. ed. rev. e atual. São Paulo: ArsPoetica/EDUSP, 1994.

TELLES, Célia Marques. A chamada lição conservadora na edição de textos. Scripta philologica. Feira de Santana, n. 5, 2009, p. 253-266.

TELLES, Célia Marques. Que textos são oferecidos aos estudantes? Revista do GELNE Grupo de Estudos Lingüísticos do Nordeste, João Pessoa, v. 5, n. 1 e 2, 2003, p. 21-28. 